\title{
Will COVID-19 change the way we teach medical physics post pandemic?
}

\author{
A. Haworth ${ }^{1} \cdot$ A. L. Fielding ${ }^{2} \cdot$ S. Marsh ${ }^{3} \cdot$ P. Rowshanfarzad ${ }^{4} \cdot$ A. Santos $^{5,6} \cdot$ P. Metcalfe $^{7} \cdot$ R. Franich $^{8}$
}

Published online: 27 July 2020

(c) Australasian College of Physical Scientists and Engineers in Medicine 2020

For many people around the world, COVID-19 brought about a rapid and massive change in the way we work. As we move forward out of the crisis, we now reflect on the way we adapted to working from home and consider if this experience will change the way we live and work in the future. On 4 May 2020, the Australian Institute of Physics (AIP) released a position statement entitled "Temporary replacement of face-to-face classes by online delivery in physics courses impacted by the COVID-19 pandemic" [1]. Whilst the report acknowledged an online approach to teaching was necessary during the crisis, it called for wider debate on how the positive outcomes of this approach can be integrated into teaching practices without losing sight of the successful reputation of the largely face-to-face and hands-on physics education. In this editorial, we (the course coordinators for each of Australia and New Zealand's ACPSEM accredited medical physics programs) review the content of this position statement, reflect on our own experiences as we reach the end of semester one, and consider how we will move forward for the remainder of the year and beyond.

Whilst the AIP position statement acknowledges that we still face an uncertain future, it is clear that the AIP's view is that a predominantly online mode of teaching should only

A. Haworth

annette.haworth@sydney.edu.au

A. L. Fielding

a.fielding@qut.edu.au

S. Marsh

steven.marsh@canterbury.ac.nz

P. Rowshanfarzad

pejman.rowshanfarzad@uwa.edu.au

A. Santos

alexandre.santos@adelaide.edu.au

P. Metcalfe

metcalfe@uow.edu.au

R. Franich

rick.franich@rmit.edu.au be viewed as a short-term measure to deal with a temporary emergency. The comments are largely based on highschool and undergraduate teaching. We therefore ask if the arguments against continuing online apply to the ACPSEM accredited postgraduate medical physics courses? The arguments presented by the AIP for returning to predominantly face-to-face teaching are based on preserving the excellent reputation of Australian physics teaching which is based on (a) the predominantly face-to-face teaching methods and the hands-on curriculum (b) high levels of student-student and teacher-student interaction and (c) invigilated examinations. Considering each of these points and how they relate to the pre-COVID-19 teaching we make the following observations:

1. Within Australia and New Zealand there are seven universities offering ACPSEM accredited medical physics postgraduate programs. Five of these universities provide a Master's by coursework program, one university offers a Master's by research (Adelaide) and one university (RMIT) offers both a coursework and research program. For the Master's by research programs, these are offered remotely only to hospital based medical

1 School of Physics, University of Sydney, Sydney, Australia

2 Science \& Engineering Faculty, Queensland University of Technology, Brisbane, Australia

3 School of Physical and Chemical Sciences, University of Canterbury, Christchurch, New Zealand

4 Department of Physics, University of Western Australia, Perth, Australia

5 School of Physical Sciences, University of Adelaide, Adelaide, Australia

6 Department of Medical Physics, Royal Adelaide Hospital, Adelaide, Australia

7 Centre for Medical Radiation Physics, University of Wollongong, Wollongong, Australia

8 School of Science, RMIT University, Melbourne, Australia 
physicists and the coursework components are either fully (Adelaide) or partially (RMIT) provided online. For the six Master's by coursework programs, lectures have predominantly been delivered face-to-face. Hence, we conclude that for the Master's by coursework programs, traditionally, the teaching style is face-to-face.

2. Following the enforced transition to online teaching, a variable level of student-student and teacher-student interaction was reported amongst the course coordinators. Most agreed that with a relatively small number of postgraduate students (10-25), traditionally, interaction between teacher and students was high, and that students were often willing to engage in class discussion. Others reported poor attendance at lectures, dropping substantially as semester progressed. In some cases, this could be attributed to the fact that lectures were typically recorded, with students preferring to watch the recordings at their convenience. To encourage students to develop a level of independence as they prepare for a clinical or academic role, universities are moving away from the traditional "didactic" style of teaching towards "flipped learning model" [2] or tutorial style teaching, whereby students are given resource material to read or watch ahead of the scheduled lecture and then expected to participate in group discussion with lecturer facilitation. Hence a style of "blended learning" is increasing in popularity [3]. This promotes problem solving skills and results in a greater depth of understanding of the topic. The course coordinators agreed that delivering this style of teaching this semester was challenging, but it did get easier as the semester progressed as students and teachers adapted to using their online system. Most course coordinators agreed that they were aware that students traditionally formed their own "chat groups" either through university provided forums, but often through social media sites that excluded the teachers. It was unclear if this was diminished this semester, but highly likely as universities went into lockdown very soon after the start of semester providing limited opportunity for study groups to be formed.

3. Traditionally our exams have been invigilated either in the exam hall with well-spaced desks and a trained invigilator, or, by an approved local invigilator in the case of the online coursework students (Adelaide). Maintaining academic integrity for exams that have been forced "online" without any formal invigilation this semester has been the subject of endless hours of debate, workshops, emails and phone calls. Historically, each of the Australian universities offering accredited courses demands a high degree of academic integrity for the courses they offer. across the universities a range of methods aimed at maintaining academic integrity were formulated for students who would mostly be com- pleting exams in an uncontrolled environment. These included using Zoom (Zoom video communications, CA, USA) to monitor students while they completed the exam and using a style of questioning requiring more critical thinking therefore limiting the value of searching through notes or using online searches. All applied a time limit to reduce the opportunity to search notes and the internet for solutions, but completion of the exams ranged from typing answers online through the local learning management system [e.g. Blackboard (Blackboard Inc, USA), Canvas (Instructure Inc, UT, USA), Moodle (Moodle Pty, Ltd, WA Australia)] to upload of handwritten solutions within 3-6 h of the questions being released. The online examination process also forced most of us into making this exams "openbook" style, a practice historically not used in any of the courses. We all agreed that providing exams online was challenging, but this was largely based on lack of experience and the need to act quickly - these types of changes in the way we manage our courses typically take around two years to implement following a thorough review and wide ranging research. No doubt we will learn a lot from our experience this semester, it is too early to say if our exams will be of lesser academic integrity than pre COVID-19.

The discussion so far has been based mostly on preserving our reputation for high quality teaching and academic integrity. As with most physics (non-research based) courses, some level of practical hands-on training has been considered part of normal medical physics postgraduate training. This semester, the course coordinators found inventive ways of providing students with a virtual hospital experience. Whilst some had access to research institutes (e.g. Ingham Institute) that permitted some limited access for students, most of us just hoped things would get better next semester whilst we dealt with online teaching and exams. With semester two planning already under way, it appears that online teaching will persist in at least four of the six coursework programs next semester. Most reported that on-campus labs and potentially some hospital-based visits may be possible depending on local restrictions. Whilst our colleagues may start to resume normal hospital work, most universities acknowledge that significant harm was done in taking the organizations into lockdown at short notice, and furthermore, with many international students already returned to their home countries, we cannot expect them to return to Australia to resume their studies next semester. With the realization that online teaching is here to stay for most of us for at least one more semester, the course coordinators are discussing methods of sharing our virtual labs in a way to support one another and distribute the workload. Indeed, over recent years, the course coordinators 
have worked collegially on a number of initiatives across the teaching and research domains, and this crisis may present yet another opportunity to build on those co-operations [4-6].

Apart from practical training, students of an ACPSEM accredited course are also required to carry out a research project. For some universities, the research project is carried out over more than one semester. For those that provide students with a one full-time semester project this has been problematic this semester. After months of planning their projects and meetings with supervisors in the lead up to the start of semester, one-by-one hospitals either restricted or denied access leaving students and supervisors to re-design their projects. Furthermore, students returning from overseas were required to self-isolate for the first two weeks of semester putting them at significant disadvantage. Students were left very disappointed that they didn't get the hospital experience they were looking forward to.

We might conclude so far that returning to the "old-way" of teaching is the best option. However, we must also consider the positive outcomes of our experience. Also, we may need to accept that things may never return to "normal"; and, possibly the elephant in the room acknowledge that universities are under great financial distress. Small courses are always a target for cost-cutting and for our courses to survive we must consider ways to at least maintain our current student numbers and to deliver our programs in a cost-effective way [7]. Each of the universities has historically had its own "special flavor" in the way it offers its accredited programs. Such diversity is an asset to Australian students and provides an opportunity for us to learn from one another the potential merits of each approach and provide points of differentiation that are an inherent necessity in a higher education system that must exist in a competitive market. The number of international students that come to Australia is already volatile and typically relies heavily on local government support which may be subject to political issues beyond our control. We can continue to hope that students from overseas will to travel to Australia and support our student numbers so that we can remain viable, or we can be inventive and look at options such as hybrid online courses that provide options for virtual labs, projects that allow remote access to hospital systems and proctored exams.

Another point of consensus within the course coordinator group was that our largely vocational courses require the engagement of our hospital partners to provide support for research projects and a practical understanding of the theory taught in lectures. Hospital based research projects play a key role in providing quality graduates for the TEAP program. The cooperation and involvement of clinical medical physicists in these projects is highly valued. It was noted that during the height of the pandemic, hospital based medical physicists determined that hospital-based teaching should be reduced in frequency and performed off-site or cancelled [8]. Whilst we acknowledge these decisions would have largely been based on broader government or hospital directions, we hope that our hospital-based colleagues will agree that the students that they will one day employ in registrar training programs benefit from the time spent in hospitals and they will endeavor to support the return of students to hospitals as soon as practical. Indeed, we are aware that similar allied health workers such as nurses and radiation therapists were, in many instances, permitted to complete internships during the crisis, in contrast to our medical physics students.

Another impact of COVID-19 lockdown on students was the psychological effect including anxiety and mental health issues. The unprecedented situation induced uncertainties about their education, research, career progression and lives in general. It left the students in stressful conditions, particularly new international students and those in their final year. Financial pressure was another major problem for many students, especially international students with family support, when parents had lost jobs and could not support them anymore. Coordinators were mindful of the situations and tried to provide the best advice on an individual basis.

This editorial has been written in the final few weeks of semester. Over the next few weeks our students will sit their exams and we will receive the results of student surveys. The course coordinators agreed that issuing a position statement around online teaching is too premature. One of the positives of this crisis is that it has again brought us all together and our monthly meetings have been extremely productive as we've openly shared our methods of survival. We are most grateful to the ACPSEM for trusting us to work together and within our university directives to do our best to maintain the high standards of teaching and academic integrity. A position statement may be released in the future, but not without wide consultation from our hospital and industry colleagues, teachers, students and the broader community. We close with a shameless plug for the ACPSEM university special interest group. Become a member today and join the conversation on how we may learn from our experiences to continue to provide high quality, clinically relevant and cost-efficient means of teaching the next generation of medical physicists.

\section{References}

1. https://doi.org/10.1007/s13246-020-00896-x

2. Lee J, Lim C, Kim H (2017) Development of an instructional design model for flipped learning in higher education. Educ Technol Res Dev 65:427-453

3. Czaplinski I, Fielding AL (2020) Developing a contextualised blended learning framework to enhance medical physics student learning and engagement. J Med Phys 72(February):22-29. https ://doi.org/10.1016/j.ejmp.2020.03.010 
4. Thwaites DI, Franich RD, Carolan M, Fielding AL, House M, Kuncic Z, Mohammadi M, Rosenfeld A (2013) The medical physics university network: a new national collaborative inter-university initiative for [1]medical physics teaching, learning, information and research. In: 2012 Engineering and physical sciences in medicine conference. Australas Phys Eng Sci Med 36:65-141. https://doi.org/10.1007/s13246-012-0168-7

5. Thwaites DI, Franich RD, Carolan M, Fielding AL, House M, Kuncic Z, Metcalfe P, Pollard J, Rosenfeld A (2014) The academic, medical physics university network: initial activity and progress. In: Engineering \& physical sciences in medicine conference 2013, Perth, Australia, 3-7 November 2013. Australas Phys Eng Sci Med 37:153-269. https://doi.org/10.1007/s1324 6-014-0248-y

6. Thwaites DI, Carolan M, Fielding AL, Franich RD, House M, Lehmann J, Metcalfe P, Penfold S, Rosenfeld A (2016) The Australian national collaborative academic medical physics network structure, activity and outcomes. In: EPSM2015, Engineering and physical sciences in medicine. Australas Phys Eng Sci Med 39:259-354. https://doi.org/10.1007/s13246-015-0410-1

7. Fielding A, Prisciandaro JI, Orton CG (2018) Changes and demands in the higher education sector are increasingly making advanced degree medical physics programs nonviable and the profession will have to develop a new model for delivering such education. Med Phys 45(1):1-4

8. Whitaker M, Kron T, Sobolewski M, Dove R (2020) COVID-19 pandemic planning: considerations for radiation oncology medical physics. Phys Eng Sci Med. https://doi.org/10.1007/s13246-02000869-0

Publisher's Note Springer Nature remains neutral with regard to jurisdictional claims in published maps and institutional affiliations. 